\title{
Análise de Fatores Críticos de Sucesso da Gestão de Processos de Negócio em Organizações Públicas
}

\author{
Hígor M. Santos, André F. Santana, Carina F. Alves \\ Centro de Informática (CIn) - Universidade Federal de Pernambuco (UFPE) \\ Caixa Postal 50.740-560 - Recife - PE - Brasil \\ $\{$ hrms, afls2, cfa\}@cin.ufpe.br
}

\begin{abstract}
This work aims to analyze the relationship between Critical Success Factors (CSF) frequently encountered in literature to those encountered in business process management initiatives (BPM) from public sector. Best practices in BPM have been focused by organizations which aim to obtain an optimal performance. However, as the number of BPM initiatives grows, high failure rates are reported. On this context, based on CFS encountered in literature, this research aims to investigate, by a qualitative empirical study, which factors deserve more attention from public organization. As result and main contribution, it was observed that there are factors that are singular to public sector, in form of barriers and facilitators beyond the ones encountered in literature.
\end{abstract}

Resumo. Este artigo tem o objetivo de analisar a relação existente dos Fatores Críticos de Sucesso (FCS) frequentemente encontrados na literatura e na prática das iniciativas de Gestão de Processos de Negócio (Business Process Management - BPM) no Setor Público. Melhores práticas de BPM têm sido o foco das organizações que almejam alcançar um ótimo desempenho empresarial. No entanto, à medida que cresce o número de iniciativas de BPM, são registrados altos índices de falhas. Nesse contexto, busca-se investigar através de um estudo empírico de natureza qualitativa os fatores que merecem mais atenção em organizações públicas baseada nos FCS da literatura. Como resultado e principal contribuição, constataram-se fatores que são singulares no Setor Público demonstrando barreiras e facilitadores além daqueles encontrados na literatura.

\section{Introdução}

A busca constante pelo alcance dos objetivos estratégicos tem gerado nas organizações uma preocupação em aperfeiçoar continuamente seus processos de negócio. Com a operacionalização das técnicas e conceitos da abordagem de Gerenciamento de Processos de Negócio (do original em inglês: Business Process Management - BPM), torna-se possível tanto o alinhamento de visão entre as áreas estratégicas e as funcionais quanto à capacidade das organizações serem aptas a responder as mudanças do ambiente competitivo. Como definição, a OMG (Object Management Group) cita que BPM é um conjunto de técnicas para a melhoria contínua e iterativa dos processos de negócio de uma organização (OMG, 2010). Semelhantemente, Jeston e Nelis (2008) afirmam que é "a realização dos objetivos de uma organização através da melhoria, gestão e controle de processos de negócio essenciais". 
Nesse aspecto, tem-se observado que o interesse das organizações por estas práticas de gestão ou melhoria de processos tem crescido e se consolidado a cada ano (DALE, ELKJAER, et al., 2001); (ORACLE, 2008). Projeções para 2011 divulgadas por empresas especialistas em pesquisas apontam que os investimentos em tecnologias que apoiam a gestão de processos, em bilhões de dólares, são estimados em 5.1B pela Gartner $^{1}, 6.3 \mathrm{~B}$ pela Forrester ${ }^{2}$ e $5.5 \mathrm{~B}$ pela IDC $^{3}$. No entanto, apesar da alta quantidade de implantações e do grande investimento em nível mundial (ORACLE, 2008), Grover identificou que 7 em 10 projetos de melhorias em processos falharam no passado (GROVER, 1999). Para Trkman, cerca de $60-80 \%$ dos projetos de BPM têm falhado (TRKMAN, 2010) devido a várias causas, tais como: falta de apoio da alta direção; baixo ou nenhum treinamento em BPM para os usuários finais; e a falta de comunicação e cooperação interdepartamental.

Porém, quando esses fatores são bem administrados, podem gerar impactos positivos no âmbito dos projetos e alcançar o sucesso de forma planejada. Portanto, um conceito bastante consolidado na literatura que tem a característica de tratar essas causas tanto como uma barreira, como também um facilitador, é denominado de Fator Crítico de Sucesso - FCS (JESTON e NELIS, 2008). Num ambiente corporativo, FCS é definido como um número limitado de áreas em que os resultados satisfatórios assegurarão um desempenho competitivo de sucesso para o indivíduo, departamento ou organização (BULLEN e ROCKART, 1981). De forma similar, Bruno e Leidecker (1984) definem FCS como aquelas características, condições ou variáveis que, quando devidamente sustentadas, mantidas ou administradas, podem ter um impacto significativo no sucesso da competitividade de uma empresa.

Observa-se que na maior parte desta década, BPM se manteve como um dos principais tópicos entre empresas de consultoria quando se trata, por exemplo, de melhorias de processos, relacionamento com clientes e cadeia de valor. Para Trkman (2010), os artigos científicos se preocuparam bastante em descrever o que realmente significa gestão de processos, do que é constituído, como deve ser usado, entre outros aspectos. Bandara, Gable e Rosemann (2005) ressaltam que apesar de existir muita investigação sobre técnicas de modelagem de processos e ferramentas correspondentes, existe pouca pesquisa empírica sobre os fatores de sucesso em projetos BPM e o monitoramento destes após o sucesso. Ressalta-se que na pesquisa bibliográfica deste trabalho não foi tomado conhecimento sobre pesquisas com esse foco no Setor Público.

Visando preencher esse espaço, a principal contribuição deste artigo é caracterizar os FCS específicos em iniciativas de BPM no Setor Público através de um estudo empírico de caráter exploratório que mescla a análise dos fatores críticos de sucesso de projetos BPM encontrados na literatura e em organizações do Setor Público. Como a maioria dos trabalhos da literatura não aborda os FCS em um contexto específico, o objetivo geral desta pesquisa é analisar a relação existente dos fatores críticos mais relevantes encontrados na literatura e nas organizações pesquisadas do

\footnotetext{
${ }^{1}$ Michele Cantera et al., "Forecast: Portal, Process and Middleware Software, Worldwide, 2006-2011, Update", Gartner, September 2007.

2 “BPMS Revenue to Reach \$6.3 Bilion by 2011”, Forrester, July 2007.

3 “Worldwide Business Process Management Suite 2007-2011 Forecast and 2006 Vendor Shares", IDC, August 2007.
} 
Setor Público que podem levar iniciativas de BPM ao sucesso. Os objetivos específicos pretendem responder as seguintes questões de pesquisa (QP):

- QP1: Quais são os Fatores Críticos de Sucesso de iniciativas de BPM relevantes encontrados na literatura?

- QP2: Quais são os Fatores Críticos de Sucesso de iniciativas de BPM relevantes encontrados no Setor Público?

- QP3: Qual é a relação entre os Fatores Críticos de Sucesso de iniciativas de BPM da literatura e Setor público?

No entanto, antes de investigar profundamente quais são os FCS, é preciso anteriormente definir o que é "sucesso", já que dependendo do ponto de vista, seja da organização, diretoria ou gestão, o conceito de sucesso em projetos de gestão de processos pode variar. Para guiar esta pesquisa, como não é analisada uma organização específica, foi adotada uma definição genérica: o sucesso em gestão de processos é alcançado quando, a partir do planejamento da iniciativa, se obtêm os resultados esperados.

Este trabalho está estruturado da seguinte forma: a Seção 2 apresenta o método utilizado para conduzir a pesquisa; a Seção 3 descreve os resultados obtidos; e a Seção 4 discute as conclusões e as oportunidades para futuras pesquisas.

\section{Método de Pesquisa}

Esta pesquisa tem como natureza um estudo exploratório qualitativo a fim de identificar e relacionar, com base na literatura e na investigação de organizações do Setor Público, os fatores que são críticos para alcançar o sucesso de iniciativas de BPM. Dentre os tipos de pesquisa qualitativa citados por Merriam (2009), esta pesquisa se configura como estudo qualitativo básico, que tem como características: obter o entendimento do conteúdo pesquisado, uso de amostra intencional; a coleta de dados pode ser realizada via entrevistas, observações e documentos; a análise dos dados é indutiva e comparativa; e os resultados são descritos também de forma indutiva e rica em categorias.

Inicialmente, para responder a primeira questão de pesquisa (QP1), presente na Seção 1, foi realizada uma pesquisa bibliográfica ad-hoc, cobrindo livros, whitepapers de consultorias, artigos de jornais e periódicos acadêmicos. Em algumas situações, foram buscadas também as referências citadas nos trabalhos pesquisados. Posteriormente, para identificar quais são os FCS mais relevantes para o Setor Público, foi realizado um estudo empírico em quatro organizações públicas ${ }^{4}$ que se encontram numa esfera de Governo Estadual e que estão desenvolvendo iniciativas em BPM. Uma breve descrição destas se encontra a seguir:

Organização A: concentra-se em atividades relacionadas a recursos humanos, aquisições e contratos de administração. Seus clientes são todas as outras unidades governamentais do Estado (cerca de 70 organizações). Todos os participantes do estudo eram provenientes de uma unidade organizacional responsável pela concepção e gestão de processos do setor de Recursos Humanos. Os papeis dos indivíduos que fizeram

\footnotetext{
${ }^{4}$ Conforme acordado com os participantes, todos os nomes das organizações foram omitidos.
} 
parte da pesquisa são: um líder de equipe BPM, dois analistas de processos, um gerente de Recursos Humanos funcional e um chefe de departamento (considerado patrocinador da iniciativa BPM).

Organização B: suas atividades destinam-se ao suporte de serviços educacionais e políticos. Seus principais clientes são os alunos adolescentes da sociedade. Os participantes pesquisados trabalhavam numa unidade organizacional responsável por serviços de TI, modelagem e desenho de processos. Os papéis dos participantes entrevistados são: dois analistas de processos (um deles era consultor de TI que atuou em tempo parcial como analista de processos), um gerente de Recursos Humanos funcional (que é cliente BPM) e um chefe de departamento de serviços de TI (que atua como patrocinador BPM).

Organização C: trabalha com serviços sociais e políticos de direitos humanos. Seus clientes são a população em geral, especialmente as pessoas com necessidades sociais que necessitam de apoio governamental. Neste estudo, os participantes foram principalmente de duas unidades organizacionais responsáveis por, respectivamente, serviços de TI, e as políticas e serviços especiais para pessoas com limitações físicas. Todos eles estavam trabalhando em um projeto de gestão de processos que visa melhorar os serviços para pessoas com deficiência física. Participaram do estudo: dois consultores de TI (que atuam como analistas de processos em tempo parcial), um chefe do departamento de serviços de TI (que atua como patrocinador BPM), dois gerentes funcionais (que são clientes BPM) e um diretor (que também é cliente BPM).

Organização D: tem seu foco em trabalhos sobre as políticas de desenvolvimento de serviços turísticos. Seus clientes são formados pela população local, turistas e empresas envolvidas na indústria turística. Neste estudo, fizeram parte dois analistas de processos, um diretor de planejamento (que atua como patrocinador BPM) e dois assessores jurídicos (de um departamento jurídico, na qualidade de clientes de BPM).

Portanto, a fim de obter insumos suficientes para responder a segunda questão de pesquisa (QP2), as perguntas aplicadas aos participantes tiveram a finalidade de obter conhecimento em profundidade sobre como a iniciativa de BPM estava sendo realizada, como surgiu, quais eram os objetivos, quem estava envolvido, se havia padrões e metodologias, áreas afetadas pela iniciativa, e por fim, as barreiras e os facilitadores que tinham encontrado até o momento. Para esta pesquisa, é considerada iniciativa de BPM quando a organização tem, no mínimo, o objetivo de identificar e melhorar seus processos de negócio. Quanto à relevância dos FCS, esta pesquisa adotou uma estratégia para classificá-los da seguinte forma: quanto mais eles são evidenciados, seja na literatura ou nas entrevistas realizadas nas organizações do Setor Público, mais relevantes eles se tornam. Isto estará melhor descrito na seção dos Resultados.

Quanto ao critério de escolha dos participantes, ou seja, as organizações e os sujeitos respondentes das entrevistas, designou-se de forma intencional visando a riqueza dos dados, como sugerido por (MERRIAM, 2009). Nesta escolha, foram pesquisadas algumas pessoas com reconhecido conhecimento da esfera de Governo a fim de fornecer informações sobre possíveis organizações candidatas. E ao final de cada entrevista, foi utilizada a estratégia em cadeia ou "bola de neve" (RUNESON e HÖST, 2008), na qual os participantes iniciais sugerem outros casos de iniciativas de BPM ou pessoas influentes. 
Ao todo, 20 profissionais das quatro organizações participaram da pesquisa através de entrevistas e grupo focal. Os participantes desempenham as seguintes funções: Cliente BPM, Analista de Processos, Líder BPM e Patrocinador da Iniciativa. Os dados foram coletados primeiramente por meio de 13 entrevistas, das quais apenas duas ocorreram em dupla e as demais individuais. Participaram destas entrevistas quatro profissionais da Organização A, quatro da Organização B, três da Organização C e quatro da Organização D. As entrevistas foram semi-estruturadas, pois este tipo de estratégia de coleta de dados permite um conjunto flexível de perguntas e respostas, no qual é possível improvisar para explorar temas de interesse emergentes (MERRIAM, 2009), (RUNESON e HÖST, 2008). Todas elas foram gravadas em áudio. A medida que iam sendo realizadas, ocorriam as transcrições delas numa planilha para que de forma iterativa, categorias pudessem ser extraídas em formato de Fatores Críticos de Sucesso.

A fim de validar e tornar as informações extraídas das entrevistas semiestruturadas mais confiáveis, após as transcrições e análises foi realizado um grupo focal que reuniu 12 participantes. Os participantes estavam divididos da seguinte forma: quatro eram da Organização A, um da Organização B, cinco da Organização C e dois da Organização D. No grupo focal, após a apresentação dos principais conceitos e objetivos da pesquisa, os participantes foram incentivados tanto a falar de questões que não foram suficientemente abordadas nas entrevistas como também descrever e discutir em grupo sobre os facilitadores e barreiras das iniciativas de BPM. Com isso, procurouse responder a questão de pesquisa (QP2) que trata dos FCS relevantes para o setor público. E por fim, a resposta para questão de pesquisa (QP3) foi obtida através de discussão e consenso entre os autores a partir da comparação entre os resultados da QP1 e QP2.

\section{Resultados}

Os resultados da pesquisa são apresentados em subseções visando responder as questões de pesquisa contidas na Seção 1. Para cada subseção foi criada uma tabela para demonstrar e discutir os achados e as evidências correspondentes, e em seguida elas são discutidas. No entanto, antes de abordar de fato as questões de pesquisa, algumas considerações sobre os resultados são dadas a seguir.

Pode-se perceber que existe ainda uma baixa atenção para com os Fatores Críticos de Sucesso em iniciativas de BPM tanto na literatura, devido a pouca quantidade de trabalhos existentes com esse foco, quanto no Setor Público, em que se observaram situações de falta de planejamento consistente e planos de contingência para lidar com os FCS em todo o ciclo de vida do projeto. Há na internet blogs e grupos de discussões que apontam dificuldades, explicações de como não falhar em projetos BPM, o porquê e onde eles tendem a dar errado.

No entanto, de acordo com a pesquisa bibliográfica realizada, Trkman (2010) é o único trabalho acadêmico que aborda especificamente os FCS em iniciativas de BPM. Apesar de não ser o foco principal dos trabalhos, estão presentes em Jeston e Nelis (2008) e ABPMP (2009) seções dedicadas aos FCS. Artigos realizados por empresas de consultorias também foram analisados, tais como: (SMITH e FURT, 2009), (DAVIDSON e HOLT, 2008) e (LOCK, 2008). Além desses citados, outros trabalhos relacionados contribuíram para a formação da lista dos Fatores Críticos de Sucesso mais 
relevantes presentes na literatura: (ZUR MUEHLEN, 2004), (BANDARA, GABLE e ROSEMANN, 2005), (RAVESTEYN e BATENBURG, 2010), e (PRITCHARD e ARMISTEAD, 1999).

De acordo com a análise dos dados do estudo empírico, pode-se afirmar que as organizações participantes desta pesquisa encontram-se em estágio inicial nas iniciativas de BPM, tendo começado suas atividades há cerca de dois anos. Este fato pode contribuir para a existência de mais barreiras do que facilitadores neste momento das iniciativas. Ao relacionar as iniciativas que estão sendo desenvolvidas nas quatro organizações, puderam ser constatadas inúmeras diferenças e semelhanças. Alguns exemplos de diferenças são: somente uma organização tem uma equipe com papéis e responsabilidades bem definidos para o trabalho em processos. Porém nas outras organizações há uma carência de pessoal nessa área; em algumas organizações, as pessoas precisam dividir suas tarefas diárias para executar atividades de levantamento e melhoria de processos de negócio, em outras, as pessoas trabalham exclusivamente nos projetos de gestão de processos. Portanto, isso indica que algumas organizações do Setor Público estão mais avançadas ou priorizam mais a iniciativa em gestão de processo que outras.

É possível citar dois exemplos comuns de semelhança entre elas. O primeiro é a falta de capacitação e treinamento específico para os envolvidos na condução das iniciativas, pois em alguns casos elas possuem apoio de consultorias ou pessoas externas com expertise em BPM, como também estudam a teoria por si só e vão aprendendo com a prática. E o segundo é a existência de uma grande motivação do pessoal que está conduzindo as iniciativas em gestão e melhoria dos processos. A seguir, são apresentadas evidências que visam responder as questões de pesquisa.

\subsection{QP1: Quais são os Fatores Críticos de Sucesso de iniciativas de BPM encontrados na literatura?}

Foram observados diversos fatores na literatura pesquisada que são considerados críticos para qualquer iniciativa de BPM, alguns trabalhos apresentam nomenclaturas para os FCS diferentes dos outros. Portanto, fatores que têm o mesmo significado foram padronizados para uma melhor representação nesta pesquisa. São apresentados na Tabela 1, por ordem de frequência de citação nos trabalhos, os FCS em iniciativas de BPM. Os números presentes na coluna Evidência na Literatura fazem referência aos seguintes trabalhos: $[1=($ ABPMP, 2009), $2=($ DAVIDSON e HOLT, 2008), $3=(\mathrm{FNQ}$, 2005), 4= (JESTON e NELIS, 2008), 5= (LOCK, 2008), $6=($ PRITCHARD e ARMISTEAD, 1999), $7=($ SMITH e FURT, 2009), $8=($ TRKMAN, 2010)].

Tabela 1. FCS em BPM evidenciados na literatura

\begin{tabular}{l|l}
\hline \multicolumn{1}{c|}{ Fatores Críticos de Sucesso } & \multicolumn{1}{c}{ Evidência na Literatura } \\
\hline Metodologia Estruturada de Implantação & {$[1],[3],[4],[5],[6],[7],[8]$} \\
\hline Mudança Organizacional & {$[1],[2],[4],[5],[6],[8]$} \\
\hline Treinamentos da Equipe de Processos & {$[2],[3],[4],[6],[7],[8]$} \\
\hline Atuação de um Patrocinador Executivo & {$[1],[4],[6],[7],[8]$} \\
\hline Pessoas e Empowerment & {$[2],[3],[4],[6],[8]$} \\
\hline Alinhamento Estratégico & {$[1],[4],[6],[8]$} \\
\hline
\end{tabular}




\begin{tabular}{l|l}
\hline Medição e Monitoramento da Iniciativa & {$[1],[4],[7],[8]$} \\
\hline Automação de Processos & {$[1],[4],[6],[8]$} \\
\hline
\end{tabular}

ABPMP (2009) é um guia de conhecimento de BPM composto por uma visão abrangente das questões, melhores práticas e lições aprendidas adquiridas por consultores da Associação dos Profissionais de BPM. Neste guia, é afirmado que os esforços que envolvem o sucesso da gestão de processos consideram um conjunto de fatores, incluindo práticas organizacionais e tecnológicas. Davidson e Holt (2008) descrevem em seu artigo motivos que os projetos BPM tendem a falhar. Eles apontam como causas principais a falta de uma visão estratégica, projetos de baixo impacto e gestão de mudanças. A FNQ (2005) ressalta que além de estratégias de gestão e planos para entregar produtos de qualidade aos clientes, as pessoas são a chave do sucesso para as iniciativas de BPM e afirma que é preciso elaborar programas de incentivo para haver maior participação e colaboração no ambiente interno à organização. Jeston e Nelis (2008) exibem em seu livro boas práticas para obter sucesso em iniciativas de BPM, onde eles dedicam um capítulo aos FCS mais comuns nestes tipos de projetos. Lock (2008) apresenta um relatório de pesquisa com 232 empresas que têm iniciativas de BPM e demonstra as melhores práticas e com o que se deve tomar cuidado. Entre outros fatores, destacam-se o alinhamento da TI com os processos de negócio, apoio da alta direção e investir no capital humano.

Pritchard e Armistead (1999) abordaram organizações europeias a fim de investigar: a importância de BPM para os gestores; se as organizações têm um entendimento comum de BPM; e como as organizações europeias estão implantando as práticas de BPM. Com isso, eles identificaram diversas lições aprendidas que podem ser vistas como FCS nesta pesquisa, por exemplo, alinhar BPM aos programas estratégicos, assegurar a clareza da abordagem BPM, e construir uma base de conhecimento treinando as pessoas nos processos de negócio. Smith e Furt (2009) discutem em seu artigo um conjunto de 10 fatores que mais causam falhas em iniciativas de BPM e chegam à conclusão que os principais fatores não estão ligados a questões técnicas da abordagem BPM, e sim de pontos ligados a organização, tais como, estratégia, pessoas e cultura. Por fim, Trkman (2010) realizou um estudo empírico numa empresa bancária da Slovênia e propôs um framework teórico que auxilia na identificação dos FCS.

\subsection{QP2: Quais são os Fatores Críticos de Sucesso de iniciativas de BPM encontrados no Setor Público?}

Durante as entrevistas, foi solicitado aos participantes que indicassem facilitadores e barreiras em suas iniciativas de BPM. O conceito de FCS foi comprovado ao ter conhecimento que para uma organização um fator pode ser bastante positivo, já para outra é algo visto como uma barreira. E alguns fatores foram identificados apenas como facilitadores ou apenas como barreiras. Com a realização do grupo focal, houve a oportunidade de validar os fatores críticos, além de estimular os participantes a pensar e discutir outros facilitadores e barreiras além daqueles que tinham sido identificados nas entrevistas.

Nesse aspecto, foram criadas categorias no nível de Fator Crítico de Sucesso, de forma a priorizar aqueles que tiveram maior grau de ocorrência nas entrevistas, como pode ser visto na Tabela 2. A fim de evidenciar os FCS, na segunda coluna são 
apresentados trechos das falas dos participantes de acordo com a sua função na iniciativa. E para uma melhor explanação, na terceira coluna está descrito se o FCS é visto como um facilitador ou uma barreira para aquela organização que o citou. Após a tabela, tem-se uma discussão dos fatores que foram encontrados também na literatura (Tabela 1), pois a Seção 3.3 apresenta de forma mais detalhada os FCS identificados apenas no Setor Público.

Tabela 2. FCS em BPM evidenciados no Setor Público

\begin{tabular}{|c|c|c|}
\hline $\begin{array}{l}\text { Fator Crítico de } \\
\text { Sucesso }\end{array}$ & Evidência no Setor Público & $\begin{array}{l}\text { Barreira ou } \\
\text { Facilitador }\end{array}$ \\
\hline $\begin{array}{l}\text { Metodologia } \\
\text { Estruturada de } \\
\text { Implantação }\end{array}$ & $\begin{array}{l}\text { Org. D - Analista de Processos: "Não há uma metodologia padrão. Nós } \\
\text { somos solicitados, participamos de reuniões como ouvinte, desenhamos o } \\
\text { processo, marco outra reunião com a pessoa interessada e realiza } \\
\text { entrevistas direcionadas sobre o processo". }\end{array}$ & Barreira \\
\hline $\begin{array}{l}\text { Burocracia e cultura do } \\
\text { Setor Público }\end{array}$ & $\begin{array}{l}\text { Org. C - Analista de Processos: “Apesar das pessoas quererem trabalhar, } \\
\text { a 'coisa' funciona de forma muito lenta por causa de burocracias. } \\
\text { Dependem de várias reuniões, editais, licitações, etc.”. }\end{array}$ & Barreira \\
\hline \multirow{2}{*}{$\begin{array}{l}\text { Treinamento da Equipe } \\
\text { de Processos }\end{array}$} & $\begin{array}{l}\text { Org. B - Analista de Processos: "Dado que é o nosso primeiro projeto de } \\
\text { BPM, não temos uma visão clara sobre como fazer as coisas". }\end{array}$ & Barreira \\
\hline & $\begin{array}{l}\text { Org. A - Líder BPM: "A nossa equipe é bastante heterogênea, tem gente } \\
\text { de diversas áreas, por isso treinamos todas as pessoas que entram neste } \\
\text { departamento". }\end{array}$ & Facilitador \\
\hline $\begin{array}{l}\text { Atuação de um } \\
\text { Patrocinador Executivo }\end{array}$ & $\begin{array}{l}\text { Org. D - Analista de Processos: "Existe uma real intenção de melhorar } \\
\text { os processos. As ações do governador ajudam as iniciativas, mesmo que } \\
\text { as pessoas resistam às mudanças, eles sabem que as ordens vêm de } \\
\text { cima". }\end{array}$ & Facilitador \\
\hline \multirow{2}{*}{$\begin{array}{l}\text { Pessoas e } \\
\text { Empowerment }\end{array}$} & $\begin{array}{l}\text { Org. A - Analista de Processos: "Encontramos várias dificuldades que } \\
\text { envolvem pessoas que não queriam passar informações na modelagem } \\
\text { dos processos". }\end{array}$ & Barreira \\
\hline & $\begin{array}{l}\text { Org. B - Analista de Processos: "Me surpreendi muito aqui porque tinha } \\
\text { uma visão que em uma empresa pública ninguém trabalhava. Mas } \\
\text { percebi aqui que as pessoas trabalham muito, e são capacitadas". }\end{array}$ & Facilitador \\
\hline $\begin{array}{l}\text { Composição da Equipe } \\
\text { de Processos formada } \\
\text { por pessoal interno }\end{array}$ & $\begin{array}{l}\text { Org. B - Líder BPM: "Pelo fato das iniciativas em processos terem } \\
\text { começado a partir do pessoal interno, foi algo que facilitou o nosso } \\
\text { trabalho". }\end{array}$ & Facilitador \\
\hline $\begin{array}{l}\text { Histórico de falhas em } \\
\text { projetos realizados por } \\
\text { consultorias }\end{array}$ & $\begin{array}{l}\text { Org. A - Analista de Processos: "Nós temos reuniões introdutórias para } \\
\text { deixar os usuários cientes de como vamos trabalhar, diferente de como } \\
\text { eles mesmo diziam: 'ah... isso algumas consultorias já vieram por aqui e } \\
\text { não deixaram nada, ou deixaram muito pouco, sugou tudo da gente, } \\
\text { deixou a proposta para o governo, levou o dinheiro pra eles e implantar } \\
\text { muito pouco"”. }\end{array}$ & Barreira \\
\hline \multirow{2}{*}{$\begin{array}{l}\text { Legislação atual } \\
\text { dificulta mudança nos } \\
\text { processos }\end{array}$} & $\begin{array}{l}\text { Org. A - Analista de Processos: "Algumas de nossas ações esbarram na } \\
\text { lei, por exemplo, em legislação ou estatuto do setor público". }\end{array}$ & Barreira \\
\hline & $\begin{array}{l}\text { Org. C - Analista de Processos: "Um ponto desfavorável é a indefinição } \\
\text { da lei, só que alguns órgãos estão conversando para mudar essa lei". }\end{array}$ & Barreira \\
\hline $\begin{array}{l}\text { Clientes BPM com } \\
\text { experiência baixa em } \\
\text { ferramentas de TI }\end{array}$ & $\begin{array}{l}\text { Org. D - Analista de Processos: "As pessoas atingidas pela iniciativa não } \\
\text { foram capacitadas para utilizar as ferramentas e muitas delas têm } \\
\text { dificuldade com o manuseamento de computadores". }\end{array}$ & Barreira \\
\hline $\begin{array}{l}\text { Integração entre as } \\
\text { organizações do Setor } \\
\text { Público }\end{array}$ & $\begin{array}{l}\text { Org. C - Analista de Processos: "As Secretarias não são integradas, o } \\
\text { que gera retrabalho, ou seja, o que é feito em uma Secretaria, poderia } \\
\text { ser replicado nas demais". }\end{array}$ & Barreira \\
\hline
\end{tabular}




\begin{tabular}{l|l|c}
\hline & $\begin{array}{l}\text { Org. D - Líder BPM: “Temos uma integração muito saudável com } \\
\text { algumas das Secretarias". }\end{array}$ & Facilitador \\
\hline Rotatividade de pessoal & $\begin{array}{l}\text { Org. D - Analista de Processos: “A rotatividade nesta Secretaria é muito } \\
\text { grande. Cerca de 80\% de funcionários são terceirizados”. }\end{array}$ & Barreira \\
\hline $\begin{array}{l}\text { Descontinuidade dos } \\
\text { projetos por causa da } \\
\begin{array}{l}\text { troca de Governo nas } \\
\text { Eleições }\end{array}\end{array}$ & $\begin{array}{l}\text { Org. A - Cliente BPM: "Quando há uma troca no governo, ocorre } \\
\text { frequentemente uma descontinuidade nos projetos". }\end{array}$ & Barreira \\
\hline
\end{tabular}

Das quatro organizações abordadas, apenas a Organização A tem uma proposta inicial de metodologia de implantação das iniciativas de BPM, porém ainda não suficientemente amadurecida e testada. Além disso, ela era a única que tinha seus colaboradores dedicados nas tarefas de processos e realizavam treinamentos num nível básico com os novos funcionários, embora que no início das iniciativas de BPM não houve uma capacitação devidamente estruturada da equipe de processos. Os conceitos e práticas da gestão de processos foram adquiridos através de pesquisas teóricas. Isso já a coloca numa posição acima das outras organizações em nível de maturidade BPM. Nas outras organizações, observou-se que as etapas das iniciativas são realizadas de forma $a d-h o c$, onde muitas vezes depende do contexto do projeto. Atrelado a esse fator, está o Treinamento da equipe de processos, pois, para colocar em prática todos os passos da implantação de forma correta, os responsáveis pela iniciativa precisam estar todos alinhados e bem capacitados para desempenhar esta tarefa.

Algo que chamou atenção como facilitador foi o fato de todas as organizações possuírem um patrocinador executivo atuando e apoiando diretamente na iniciativa BPM. Que segundo os participantes, além de contribuir na obtenção de recursos necessários a realização dos projetos, reflete também nos clientes BPM que passam a colaborar com menos resistência. $\mathrm{O}$ fator Pessoas e Empowerment teve características diferentes de uma organização para outra, o que pode ser explicado tanto pela cultura das organizações quanto pela capacitação das pessoas envolvidas. Ou seja, por serem organizações públicas, onde se tem estabilidade no emprego, existem funcionários há mais de 20 anos num cargo que são bastante resistentes às mudanças, no entanto, se tornaram especialistas naquele determinado trabalho. Com isso, cabe a estratégia administrar esse fator com técnicas que motivem as pessoas desempenharem seus papéis e responsabilidades com eficiência.

\subsection{QP3: Qual a relação entre os FCS de iniciativas de BPM da literatura e Setor público?}

Ao analisar as Tabelas 1 e 2, percebe-se que alguns FCS estão presentes em ambas, e outros apenas em uma das tabelas. Nota-se que os resultados no Setor Público apresentam apenas quatro FCS relevantes iguais aos identificados na literatura (Metodologia Estruturada de Implantação, Treinamento da Equipe de Processos, Atuação de um Patrocinador Executivo, Pessoas e Empowerment). No entanto, todos os FCS identificados na literatura (Tabela 1) foram citados nas entrevistas por pelo menos um participante, porém, esses fatores não foram caracterizados como relevantes nesta pesquisa. Como os FCS identificados na literatura são para qualquer iniciativa BPM, acredita-se que foram evidenciados fatores específicos no estudo empírico devido às características singulares do Setor Público (FERREIRA, 1999). Esses FCS são apresentados e justificados na Tabela 3 . 
Tabela 3. FCS específicos do Setor Público

\begin{tabular}{|c|c|}
\hline $\begin{array}{c}\text { Fator Crítico de } \\
\text { Sucesso } \\
\end{array}$ & Justificativa \\
\hline $\begin{array}{l}\text { Burocracia e cultura } \\
\text { do Setor Público }\end{array}$ & $\begin{array}{l}\text { Foram apontadas por todas as organizações como sendo uma barreira. Como mostra a } \\
\text { evidência da Tabela } 2 \text {, não adianta apenas as pessoas trabalharem de maneira efetiva e os } \\
\text { processos estarem alinhados, se existe diversos passos que transcendem a iniciativa, tais } \\
\text { como, editais, licitações e regimentos internos. }\end{array}$ \\
\hline $\begin{array}{l}\text { Histórico de falhas em } \\
\text { projetos realizados por } \\
\text { consultorias }\end{array}$ & $\begin{array}{l}\text { Foi detectado em mais de uma organização que vários projetos de melhorias já foram } \\
\text { iniciados e muitos desses não foram concluídos ou tiveram atrasos, gerando nas pessoas } \\
\text { sentimentos de frustração e desconfiança em outros projetos desta natureza. }\end{array}$ \\
\hline $\begin{array}{l}\text { Composição da equipe } \\
\text { de processos formada } \\
\text { por pessoal interno }\end{array}$ & $\begin{array}{l}\text { Evidenciou-se em todas as organizações que quando a equipe responsável pela iniciativa } \\
\text { BPM é composta por servidores públicos, a receptividade, como também a colaboração } \\
\text { dos clientes BPM são mais dinâmicas. }\end{array}$ \\
\hline Legislação atual & $\begin{array}{l}\text { As iniciativas de BPM nas organizações públicas pesquisadas têm como barreiras as } \\
\text { legislações que devem ser regidas obrigatoriamente, o que muitas vezes impedem certos } \\
\text { tipos de melhorias. Alguns participantes ressaltaram que algumas dessas leis ficaram } \\
\text { obsoletas gerando atrasos e retrabalho, pois não acompanharam a evolução tecnológica e } \\
\text { precisam ser modificadas para que os clientes finais recebam os serviços de modo mais } \\
\text { eficiente. }\end{array}$ \\
\hline $\begin{array}{l}\text { Clientes BPM com } \\
\text { experiência baixa em } \\
\text { ferramentas de TI }\end{array}$ & $\begin{array}{l}\text { Este fator foi discutido por algumas organizações como causa principal para atrasos, } \\
\text { retrabalhos. Um analista de processos da Organização B cita que tem receio de implantar } \\
\text { um sistema que apoie a gestão de processos porque ele acha que não vai ser bem } \\
\text { utilizado pelos clientes internos. }\end{array}$ \\
\hline $\begin{array}{l}\text { Integração entre as } \\
\text { organizações do Setor } \\
\text { Público }\end{array}$ & $\begin{array}{l}\text { Este fator foi visto como barreira e facilitador por organizações distintas. Essa integração } \\
\text { representa uma troca de experiências a fim de transmitir conhecimentos, lições } \\
\text { aprendidas para não cometer as mesmas falhas cometidas por outras organizações. }\end{array}$ \\
\hline $\begin{array}{l}\text { Rotatividade de } \\
\text { pessoal }\end{array}$ & $\begin{array}{l}\text { Apesar dos servidores públicos terem um emprego estável, grande parte dos } \\
\text { trabalhadores dessas organizações pesquisadas são terceirizados, o que ocasiona diversos } \\
\text { problemas. Por exemplo, ao sair da organização, os conhecimentos adquiridos pelo } \\
\text { funcionário são levados consigo tendo que treinar o próximo que entrar. Esse é um dos } \\
\text { principais motivos para a realização da padronização dos processos. }\end{array}$ \\
\hline $\begin{array}{l}\text { Descontinuidade dos } \\
\text { projetos por causa da } \\
\text { troca de Governo nas } \\
\text { Eleições }\end{array}$ & $\begin{array}{l}\text { As eleições ocorrem periodicamente, e dependendo de interesses políticos, os projetos } \\
\text { que vinham sendo realizados podem ser interrompidos e novos projetos são iniciados. } \\
\text { Algo que pode ser feito para tentar administrar esse fator seria criar medidas provisórias } \\
\text { para quando mudar o Governo, a equipe responsável pela iniciativa ter o mínimo de } \\
\text { desvantagens possível. }\end{array}$ \\
\hline
\end{tabular}

\section{Conclusões}

A partir de uma pesquisa bibliográfica e um estudo empírico exploratório em organizações públicas, permitiu-se agregar conhecimento à literatura com evidências sobre quais fatores devem receber atenção mais específica em iniciativas de BPM em organizações públicas. Inicialmente, o artigo apresentou conceitos-chave sobre Fator Crítico de Sucesso e Gestão de Processos de Negócio. De acordo com a pesquisa bibliográfica realizada, constatou-se que há poucos trabalhos com rigor acadêmico que abordam os FCS em iniciativas de BPM. Apenas um caso (TRKMAN, 2010) realizou estudo empírico numa instituição privada. Os FCS são mais frequentemente relatados em discussões em blogs na internet, whitepapers de empresas de consultoria, e livros sem caráter de pesquisa acadêmica. Por fim, nenhum dos trabalhos pesquisados contempla o Setor Público. Desta forma este trabalho contribui também com a literatura através de um estudo empírico que poderá servir de base para comparação com novas pesquisas. 
Os resultados da pesquisa de campo mostram que todas as organizações estudadas ainda são imaturas em suas iniciativas de BPM. Apesar da maioria dos projetos ainda estarem em fase inicial, houve a identificação de um grande número de barreiras e facilitadores, onde os mais relevantes foram categorizados neste trabalho em forma de Fatores Críticos de Sucesso. Nesse aspecto, fica evidente que desde a fase de planejamento da iniciativa BPM é preciso maior ênfase na identificação dos FCS e posteriormente, quando o projeto já estiver em andamento, focar no gerenciamento desses fatores, o que envolve atividades de monitoramento e controle visando alcançar os objetivos estratégicos da organização.

Devido ao limitado número de trabalhos, organizações pesquisadas e a baixa maturidade destas em iniciativas de BPM, torna-se impossível afirmar que os Fatores Críticos de Sucesso identificados são aplicáveis a todas as organizações públicas fora do universo pesquisado e que eles têm um mesmo grau de importância. No entanto, observou-se que alguns dos fatores identificados na literatura são também encontrados no Setor Público. Por outro lado, foram citados pelos participantes fatores singulares a este tipo de ambiente, tais como, Burocracia e cultura do Setor Público, Legislação, Integração entre os órgãos do Setor Público, Histórico de falhas em projetos de melhorias, e Descontinuidade dos projetos por causa da troca de Governo em eleições. Dessa forma, conclui-se que devem ser amplos os esforços para definir e administrar os fatores que são significativos tanto para o sucesso ou fracasso da iniciativa em gestão de processos. Como consequência, proporcionando mais eficácia a este tipo de iniciativa.

Apresenta-se como oportunidade de trabalho futuro, a necessidade de outros estudos empíricos com maior profundidade em organizações de setores específicos, tais como, setor de Tecnologia da Informação, setor bancário e organizações nãogovernamentais, com vista à identificação de singularidades em termos de FCS em iniciativas de BPM. A partir disto, é necessária a construção de guias setoriais de boas práticas que facilitem a identificação e administração dos FCS em iniciativas de BPM, visando uma maior taxa de sucesso nesse tipo de iniciativa.

\section{Referências}

ABPMP. (2009) "BPM CBOK - Guide to the Business Process Management Common Body of Knowledge". Versão 2.

BANDARA, W.; GABLE, G.; ROSEMANN, M. (2005), Factors and measures of business process modelling: Model building through amultiple case study. "European Journal of Information Systems", v. 14, n. 4, p. 347-360, 2005.

BRUNO, A.; LEIDECKER, J.(1984), Identifying and Using Critical Success Factors. "Long Range Planning", v. 17, n. 1, p. 23-32.

BULLEN, C. V.; ROCKART, J. F. (1981) "A primer on critical success factors". Massachusetts: Center for Information Systems Research, Sloan School of Management, MIT, v. 69.

DALE, B. G. et al. (2001), Fad, fashion and fit : An examination of quality circles , business process re-engineering and statistical process control. "International Journal of Production Economics", v. 73, n. 2, p. 137-152. 
DAVIDSON, M.; HOLT, R. (2008), Failure Points: Where BPM Projects Tend To Falter. "Business Performance Management". Disponivel em: $<$ http://bpmmag.net/mag/failure_bpm_projects_1201/>. Acesso em: 20 Out. 2010.

FNQ. (2005) Pessoas são a chave do sucesso. "Classe Mundial”, Case da Petroquímica da União - Fundação Nacional da Qualidade.

GROVER, V. (1999), From Business Reengineering to Business Process Change Management: A Longitudinal Study of Trends and Practices. "IEEE Transactions on Engineering Management”, v. 46, n. 1, p. 36-46.

JESTON, J.; NELIS, J. (2008) "Business Process Management, practical guidelines to successful implementations". 2a . ed. Oxford: Elsevier Ltda.

LOCK, M. (2008), BPM and Beyond: The Human Factor of Process Management. "Aberdeen Group", November.

MERRIAM, S. B. (2009) "Qualitative research: a guide to design and implementation". San Francisco: Jossey-Bass,.

OMG (2010), Business Process Management with OMG specifications. "Object Management Group". Disponivel em: $<$ http://www.bpmconsortium.org/literature.htm>. Acesso em: 05 Junho 2010.

ORACLE. (2008), The State of the BPM Market 2008. "Oracle White Paper". Disponivel em: $\quad<$ http://www.oracle.com/technologies/bpm/docs/state-of-bpmmarket-whitepaper.pdf $>$. Acesso em: 08 maio 2010.

PRITCHARD, J; ARMISTEAD, C. (1999) Business process management: lessons from European business. "Business Process Management Journal”, v. 5, n. 1, p. 10-35.

RAVESTEYN, P.; BATENBURG, R. (2010), Surveying the critical success factors of BPM-systems implementation. "Business Process Management Journal", v. 16, n. 3, p. $492-507$.

RUNESON, P.; HÖST, M. (2008), Guidelines for conducting and reporting case study research in software engineering. "Empirical Software Engineering", v. 14, n. 2, p. 131-164.

SMITH, G.; FURT, S. (2009), How (not) to Fail at BPM. "BPM.COM". Disponivel em: $<$ http://www.bpm.com/how-not-to-fail-at-bpm.html>. Acesso em: 25 Maio 2010.

TRKMAN, P. (2010), The critical success factors of business process management. "International Journal of Information Management", v. 30, n. 2, p. 125-134.

ZUR MUEHLEN, M. (2004), Organizational Management in Workflow Applications. "Information Technology and Management Journal", v. 5, n. 3, p. 271-291. 